\title{
Better design, better hospitals
}

$\mathrm{E}$ vidence-based design seeks to improve health care architecture. Proponents argue that buildings can promote healing when design decisions are based on evidence from scientific research. Although they believe that the environment influences recovery, advocates of evidence-based design usually stop short of claiming that good architecture directly cures disease. They say instead that using research to guide design can result in measurable psychologic improvements, especially increases in patient satisfaction and hospital safety and reductions in patient aggression and staff anxiety. ${ }^{1}$

Specialist health care experts worldwide have adopted evidence-based design en masse. In Canada, architects and administrators boast that their stunning new hospitals are innovative and up to date simply because the designers incorporated evidence-based design "principles.", advocacy group HealthCareCAN even claims that the potential benefits of evidence-based design make a compelling argument for renewed federal investment in the country's hospital building stock (Figure 1).

In discussions about evidence-based design today, however, one important consideration is missing. When we evaluate whether this approach to design is beneficial, we have to assess previous attempts to improve hospital design. Indeed, many of the ideas associated with evidence-based design are not recent innovations, but rather are older concepts with a long tradition within hospital design. As such, evidence-based design may be more repackaging than pioneering.

Current interest in evidence-based design stems from Roger Ulrich's widely disseminated 1984 article in Science. ${ }^{4}$ Ulrich was trained in environmental psychology. His analysis of hospital records showed that a small cohort of patients who had undergone cholecystectomy used fewer potent analgesics and had shorter stays these were the patients who had a "natural view" of "a small stand of deciduous trees" through their windows, rather than views of a "brown brick wall." Around the year 2000, Ulrich began to use the term "evidence-based design" instead of "healing design" or "healing environments," making explicit reference to the concept of evidence-based medicine developed at McMaster University in Hamilton, Ontario.

Ulrich believed that he had discovered something new about hospital design. He concluded his 1984 study with advice, saying that "hospital design and siting decisions should take into account the quality of patient window views." Curiously, however, this conclusion ignores the history of architecture. Throughout the previous century, architects and planners had already been taking views and siting into account. Designers have long advocated locating hospitals in bucolic surroundings, whenever possible, to offer patients and staff views through windows. The city of Montréal, for

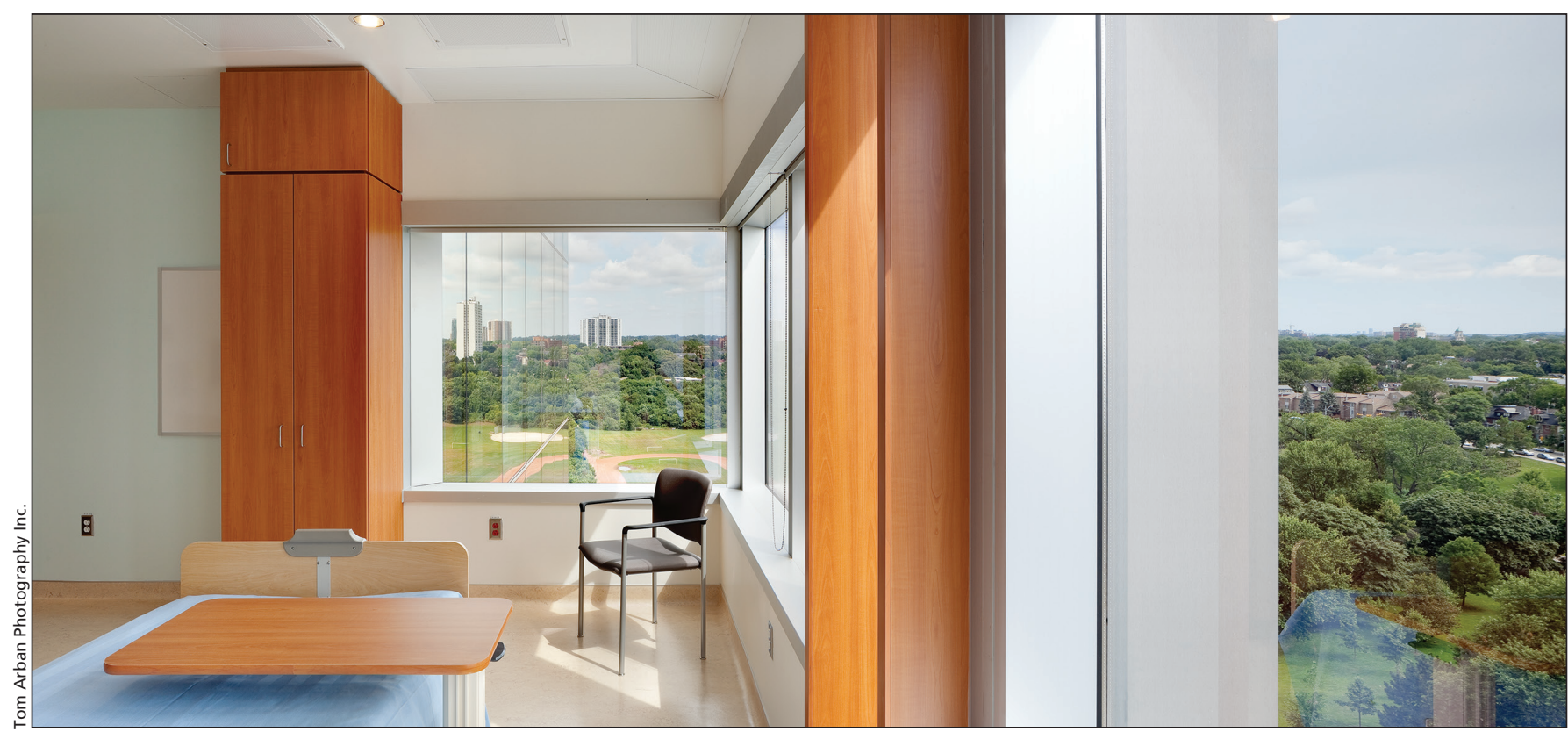

Figure 1: Proponents say that evidence-based design for hospital buildings, exemplified by this patient care unit at Bridgepoint Active Healthcare in Toronto, can promote healing. 
instance, has four major hospitals built on the slopes of Mount Royal. In 1955, the Montreal General Hospital moved from downtown to a towering building on the mountain, giving the patient rooms spectacular views down over the St. Lawrence River.

For designers, windows provide more than just views. The history of hospital architecture is full of discussions about windows and their effects on patient health. In the 19th century, British hospital reformer Florence Nightingale argued for large windows. She claimed that well-ventilated hospital wards would help evacuate any miasma, the "foul air" thought to cause nosocomial infections. After the advent of the germ theory, the discovery of sunlight's bactericidal properties led to numerous design experiments with the size, shape and orientation of windows in hospital wards. Architects also took stock of the psychologic benefits of daylight. For instance, in the hospital he planned for Venice in 1963, celebrated Swiss architect Le Corbusier based the ward design on the patient's relationship to daylight. He proposed overhead windows for when patients would be confined to bed, and horizontal windows in the wall for when patients would be mobile.

Hospital architecture is rich in such examples of ideas purportedly motivated through new scientific research that already exist as part of architectural practice. For instance, Ulrich has also advocated art in hospitals. ${ }^{5} \mathrm{He}$ believes that recent research clearly shows that seeing certain kinds of art can directly benefit patients. Yet this idea has a long history. At the beginning of the 19th century, the influence of art on healing had already been taken up by French architect Henri Labrouste, designer of the famous reading room of the Bibliothèque nationale de France. "If I were to make a hospital, I would put paintings in all the rooms," he wrote. "In the end, I am one of those people who believe that the arts have an influence on health."6

Finally, the current wave of evidence-based design also echoes attempts after World War II to incorporate computer-oriented techniques into hospital planning. As computers moved beyond specialized academic and military uses, there was great hope that they could revolutionize hospital design. Computer-oriented research was promoted in the influential book Studies in the Functions and Design of Hospitals. ${ }^{7}$ The members of the interdisciplinary team who wrote the book investigated hospital design using statistics, operations research and environmental psychology. ${ }^{8}$ Historian Joseph November has shown that evidence-based medicine has its roots in the rise of biomedical computing around 1965. ${ }^{9}$ One of the protagonists in November's study, Internet pioneer and Harvard psychologist J.C.R. Licklider, initiated several well-funded research programs that used computers to manage and design hospitals in the United States. Indeed, for Licklider, the problems of management and design seemed to go together and both could be revolutionized by computing. Later studies in the US, including the operations research carried out under John D. Thompson at Yale University, pursued similar goals, using computers to investigate design problems that are still relevant today, such as how to shorten the distances that nurses walk during a day's work. In short, since 1960, reformers have argued that digital technology would make hospitals better.

One important lesson from these historic examples is that, over time, the characteristics of good hospital design have been established as much by cultural factors as by medical considerations. For instance, evidence-based design enthusiasts advocate single-bed rather than multi-bed rooms. Recent studies have shown that private rooms reduce hospital-acquired infections and improve outcomes, ${ }^{2}$ a medical argument. But the desire for private rooms also expresses a desire for privacy, a notion that varies not medically, but rather according to cultural values and practices. In the early 20th century, for instance, North American hospitals began to build pavilions with only private rooms because of social factors: hospitals wanted to attract upper- and middle-class "paying" patients and to charge them fees for hospital services. ${ }^{10}$ The result is that today we want private rooms for both medical and cultural reasons.

Of course any approach, scientific or architectural, that makes for better hospital experiences should be encouraged. The pressing question for us today seems to be whether we can use evidence-based principles to design or redesign hospitals to make them into places of healing. However, this is exactly the question that has motivated a long line of hospital designers since the 19th century. They, too, thought they were building places of healing, and the old hospitals we are eager to replace were also conceived as healing environments. In the future, then, we might become better at making hospitals if we can learn to see that the movement to improve hospital design is not an innovative, pioneering effort, but rather part of a much longer, broader, robust effort of thinking about medical facilities.

\section{David Theodore $\mathbf{P h D}$}

School of Architecture, McGill University, Montréal, Que.

\section{References}

1. Lawson B. Healing architecture. Arts Health 2010;2:95-108.

2. Stall N. Private rooms: evidence-based design in hospitals. CMAJ 2012;184:162-3.

3. Milne V, Pendharkar S, Winkel G. The surprising science behind evidence-based hospital design. In: HealthyDebate.ca. Toronto: St Michael's Hospital, Li Ka Shing Knowledge Institute. Available: http:// healthydebate.ca/2014/07/topic/evidence-basedhospital-design (accessed 2016 June 4).

4. Ulrich RS. View through a window may influence recovery from surgery. Science 1984;224:420-1.

5. Ulrich RS, Gilpin L. Healing arts: nutrition for the soul. In: Frampton SB, Gilpin L, Charmel, PA, editors. Putting patients first: designing and practicing patient-centered care. San Francisco: John Wiley \& Sons; 2003:117-46.

6. Bressani M, Grignon M. The Bibliothèque SainteGeneviève and "healing architecture." In: Bélier C, Bergdoll B, Le Coeur M, editors. Henri Labrouste: structure brought to light. New York: Museum of Modern Art; 2012:94-123.

7. Studies in the functions and design of hospitals. London (UK): Nuffield Trust; 1956.

8. Theodore D. "The fattest possible nurse": architecture, computers, and postwar nursing. In: Abreu L, Sheard, S, editors. Daily life in hospital: theories and practices from the medieval to the modern. Oxford: Peter Lang; 2013:273-98.

9. November J. Early biomedical computing and the roots of evidence-based medicine. IEEE Ann Hist Comput 2011;33:9-23.

10. Adams A. The architect and the modern hospital, 1893-1943. Minneapolis: University of Minnesota Press; 2008.

This article has been peer reviewed.

CMAJ 2016. DOI:10.1503/cmaj.151228 